\title{
THE INSECT COLLECTIONS OF A PUBLIC MUSEUM ${ }^{1}$
}

\author{
By Albert P. MoRse
}

The aims of a public museum may be said to be primarily recreational and educational. Sometimes a museum is maintained also partly for purposes of preservation of material collected for or presented to a State, or other political, scientific, or educational institution. In-so-far as its collections arouse interest in and impart information about man and his environment or activities it belongs in one or both of the first two fields; if it conserves specimens for future examination by students it may claim to belong in the last also. Formerly, in most cases, all three fields were cultivated by the same institution. Of late, with the development of children's museums, there is an increasing tendency to relegate the duty of preservation to the larger, better endowed, and perhaps more scientific institutions, leaving the fields of recreation and education to be cultivated largely by the smaller museums. These are, perhaps (sometimes, at least) more closely in touch with the people of the district in which the museum is located.

Probably all of the older museums, founded in a more serious age by serious-minded people, still retain or have passed through all the phases mentioned. My statements are based upon the experience of the Peabody Museum of Salem and may need to be modified by that of others. This institution was founded as the museum of the East India Marine Society of Salem, in 1799. Its purpose was to contain such objects as the sea-captains of Salem and vicinity brought back from beyond the seas for the enlightenment and delectation of themselves and their fellow-members. It has always been open to the members of the society and their friends, - and even to the general public, by free admission tickets,-since the day of its founding, and it is thus one of the oldest public museums in the country.

${ }^{1}$ Address of the retiring President of the Cambridga Entomological Club, May 8, 1934. 
In 1867, on receipt of the (for the time) munificent gift of $\$ 140,000$ from George Peabody, a banker of London (born in South Danvers, Mass., since named Peabody in his honor), it took the name "Peabody Academy of Science," and embarked upon a career more particularly devoted to education. The natural history collections of the Essex Institute of Salem (founded in 1848) were added to its own, and in its early days, as the Peabody Academy of Science, its destinies were presided over by several men whose names were to become known later through their labors in scientific fields. I refer to such men as Frederick W. Putnam, Edward S. Morse, Alpheus Spring Packard, etc. Shortly thereafter, it met with financial reverses, and certain of its collections, notably those of the insects described by Packard, which faced almost certain destruction by pests, were turned over to the Museum of Comparative Zoölogy at Cambridge, Mass., in order to assure their preservation. A large number, it is true, remained, but, being almost continually exposed to white light, their deterioration was rapid.

In addition to the insect collections named above, material naturally accumulated in those groups which were the special study of officers of the museum; and, as the publisher of the "American Naturalist," the Museum was the recipient of more or less material sent in as payment for subscriptions to that journal. These specimens, together with those received from persons seeking information about local insects, accumulated rapidly, resulting in the formation of a collection of varied character and provenance. In addition, specimens of the local butterflies in Denton tablets, and of the commoner local moths, made by interested amateurs, had found a place in the museum collections at the beginning of the twentieth century.

With the exception of the local butterflies, these specimens were practically all pinned, and were contained in trays about $10 \times 12$ inches in size, painted white, and lined with white paper stretched on both sides of a wooden frame in an ingenious fashion devised by Prof. E. S. Morse (see Amer. Nat., vol. 1, p. 156, or Riley, C. V.-Directions for Coll. \& Pres. Insects, Bull. U. S. N. M., no. 39, p. 105). 
They were displayed in a glass-covered rail-case in the gallery of the Museum where they were for the most part continuously exposed to the damaging effects of white light. That some of the specimens became, with the lapse of years, nearly unrecognizable, is not to be wondered at.

Such was the state of things when I was placed in charge, for a period, at first, of one day per week, except during the summer. Later, the care of all the natural history collections,-geological, botanical, and zoölogical, was added to that of the insects, and the time allotted gradually increased, until all the time that I can now give has been taken.

Mr. John Robinson (a very good old-time botanist, by the way), who acted as Director during Prof. Morse's absences in Japan and on his lecture-tours, used to say that his personal knowledge of insects was limited to an acquaintance with those species most frequently brought in by children, or more or less conspicuous in themselves, - such as the house centipede, Scutigera forceps, formerly a common denizen of the city, - and the larger moths and butterflies. In time, these were supplemented by the gipsy and brown-tail moths, and by pests responsible for local outbreaks.

The persons visiting a museum who show an interest in insects comprise: 1st, the children of the vicinity, to whom the world and its wonders are new, and who do not customarily think, in the manner of their elders, of insects as small fry, unworthy of attention; 2nd, people of inquiring minds who have observed something new to them (it may be very old to an entomologist) ; 3rd, people to whom an insect has suddenly revealed itself as a possible pest, who seek information regarding it and how to control it; and 4 th, persons, old or young, who judge everything by its commercial value and hope to acquire dollars or cents by selling their captures to the Museum. (It may even be an almost totally denuded moth or butterfly or some similar worthless specimen.) These must all be treated with the utmost courtesy if one would make friends for the Museum; information and advice must be freely imparted; gifts of much-rubbed butterfly or legless grasshopper must be gratefully accepted or declined with thanks,--if you would 
have them continue to bring to you their treasures (or what they regard as such). Our only local specimen of Mantispa brunnea was captured by a resident clergyman, who had no idea of its rarity or interest, and who had previously brought in some execrable material.

What Collections of Insects Do Public Museums Need?

FIRsT,-exhibition collections, of large-sized specimens, to illustrate systematic groups and the most striking facts of life history and of damage done. These should contain inflated larvæ, and sometimes pupæ and cocoons, as well as adults. No rarities! Only common and readily replaceable specimens. (Do not submit rare specimens to destruction by white light! Use boxes with covers, or curtains for their protection). Probably enlarged models, showing the anatomy in detail, especially of the mouth-parts, would be valuable. I have not had an opportunity to try them, but I have heard that the enlarged model of a mosquito at the American Museum of Natural History in New York is a very popular exhibit. These enlarged models should show at least two or three types of mouth-parts and of life-histories.

I remember what a pleasure it used to be to study the New England collection of insects on exhibition in the Boston Society of Natural History, faded and discolored though they were. Probably in no way is it possible to convey to the mind of a novice such a good idea of the fauna of a particular region as by the exhibition of its component species.

Especially do I remember being seated at my table in the old entomological laboratory at Cornell University one morning when in breezed Prof. Comstock with a box in his hand and a small boy with a net in tow. "Give me your chloroform bottle, Mr. Morse, and I'll show you something," was his salutation. The bottle was promptly produced, its contents applied, and presently he exclaimed, "There, what do you think of that for central New York?" "Hallo", said I, as the great moth was revealed, "Erebus odora!" "Where in the world did you make the acquaintance of that creature?" said Prof. Comstock, with an expression of astonishment on his face. "Oh," said I, "the Boston Society 
of Natural History has a series of New England insects on view and among them is an example of this species." "There," said he, "I've always claimed that there was danger that the boys would use such a collection as a pony if we had one here, but what you say has nearly convinced me that such an exhibition series would be a good thing." This happened to be the first specimen of this species to be secured for the entomological collection of Cornell University.

An exhibition collection is undoubtedly a good thing if it inspires interest in the visitors to a museum, and if it can be properly protected from light. This can be done by the use of opaque curtains or by keeping it in drawers to be pulled out from a cabinet when it is desired to consult it. At the Peabody Museum, we have a considerable series of insect exhibits arranged in flat, glass-covered rail-cases protected by covers of opaque brown cloth attached along one side and removable by the inquiring visitor. Hitherto, it has rarely been necessary to cover up the specimens after inspection, persons removing the covers being unbelievably careful to replace them.

SECOND,-There should be at hand in every public museum, a reference or study collection for the benefit of the curator in charge of insects and the serious-mindied public seeking information. This should contain, so far as possible, examples of every local species and its life-history, their modes of attack and specimens of their work,-all to serve as an aid in identification and for the enlightenment of the serious student. Determinations of species should be by some recognized authority, if possible. This is the place for the rarities. Specimens should bear complete data as to locality and date of capture; ecological conditions should be stated, if possible; and taxonomic groups other than genus and species may well be indicated.

THIRD,-There should be topical or ecological collections, either illustrating the insects associated with certain plants, as visitors, pests or pollinators, or with a definite kind of environment,-insects of sandhills, ponds, streams, etc. These groups may be limited in number and should be of 
readily replaceable material. Those of pests should contain numerous specimens in order to convey subconsciously the idea of abundance.

FouRTH,-The geographical or zonal distribution of the insects of a large area can perhaps be fully as well shown by charts (preferably in conjunction with specimens) as by insects alone, and the topic is generally one of interest even to the transient visitor.

There are also to be considered the needs of the genuine scientific student resident in the vicinity, and of the schoolteacher trying to awaken an interest in the natural world in the minds of her pupils through this medium. Give them all the aid possible! "Cast your bread upon the waters and after many days it shall return unto you." Very likely you can give them specimens also.

Mr. Charles W. Johnson, formerly in charge of insects and mollusca at the Boston Society of Natural History, after a long and valuable experience wrote an article on this subject which should be read by everyone interested (see Museum Work, vol. 1, no. 5, Feb. 1919).

In closing, I wish to give a word of warning (and this advice will apply as well to other things as to insects) :-Accept no collections for an unlimited period of time or that must be kept separate from others! One is liable to find oneself handicapped ultimately by such a procedure, even if it seems wise at first. Twenty years ago we accepted at the Peabody Museum for temporary storage a very good collection of butterflies and moths in tablets. This is still useful as an exhibit: but it was accompanied by a space-consuming collection of mounted birds (some of which were useful at the time, it is true, but which no longer are), for which storage must be provided. To our disappointment, the owners have as yet shown no tendency to regard the Museum as other than a place of temporary storage of the collections, intead of, as hoped and as would naturally be expected, after a reasonable number of years, a more or less willing recipient, the collections to be made use of as seemed wisest to experienced persons. 

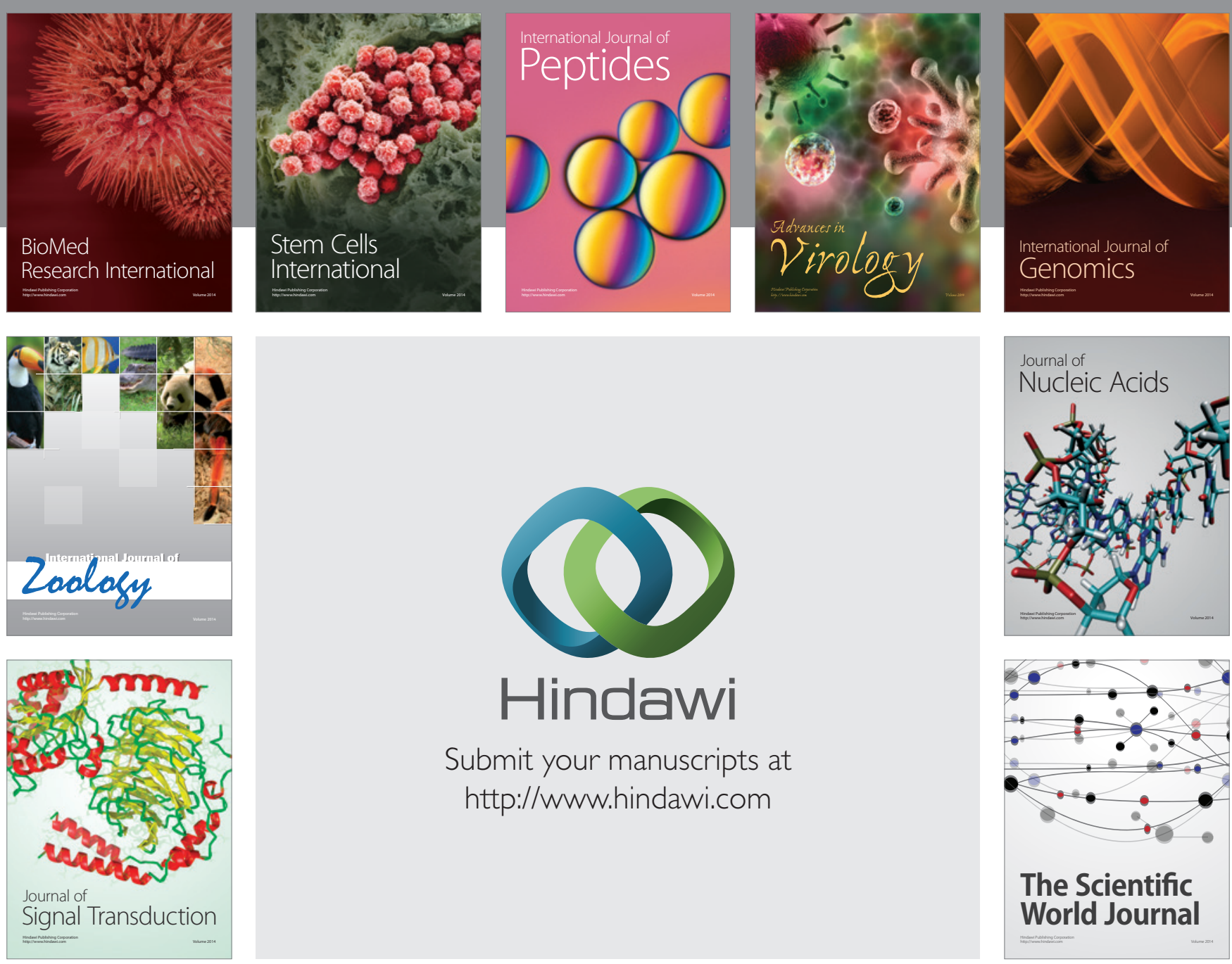

Submit your manuscripts at

http://www.hindawi.com
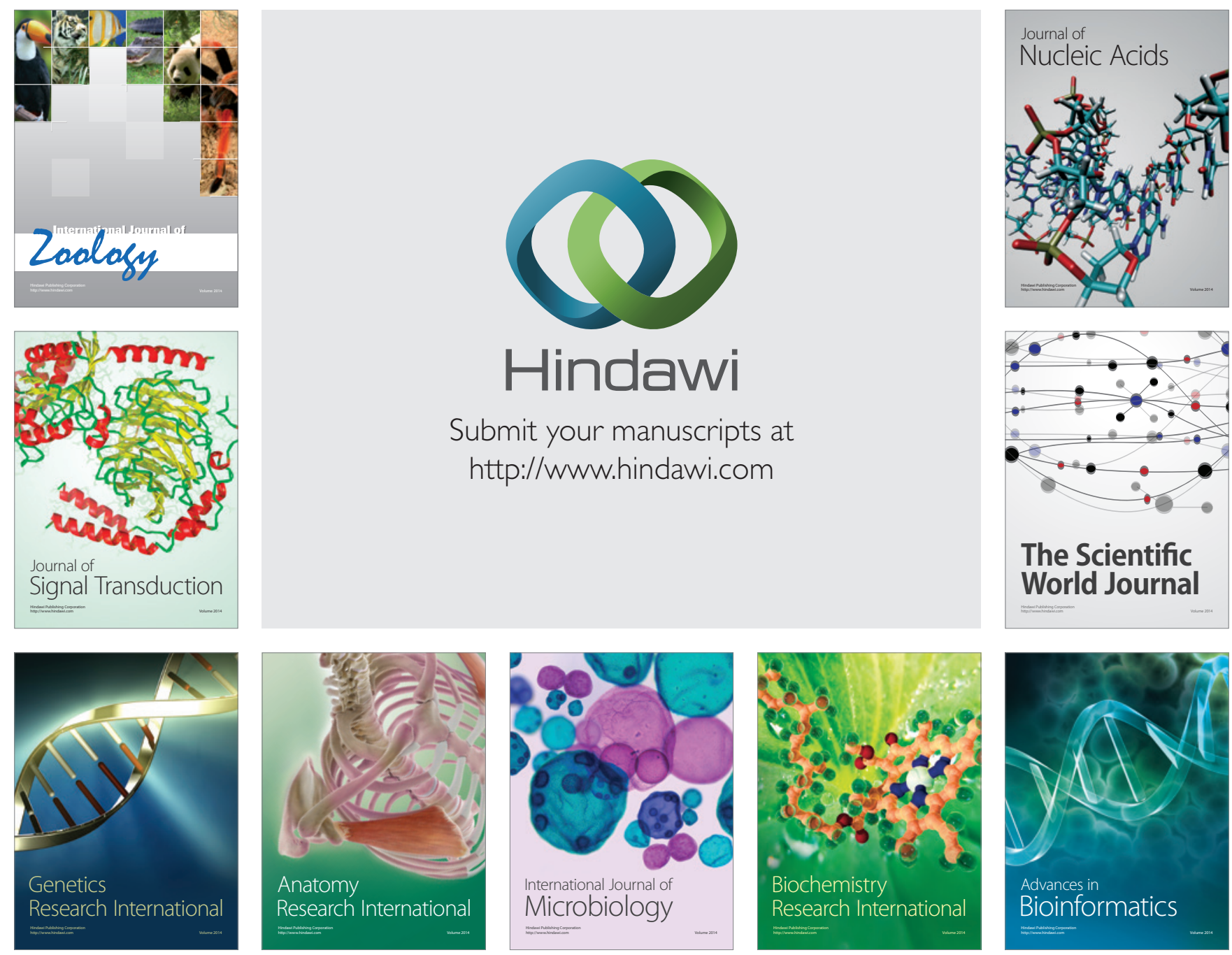

The Scientific World Journal
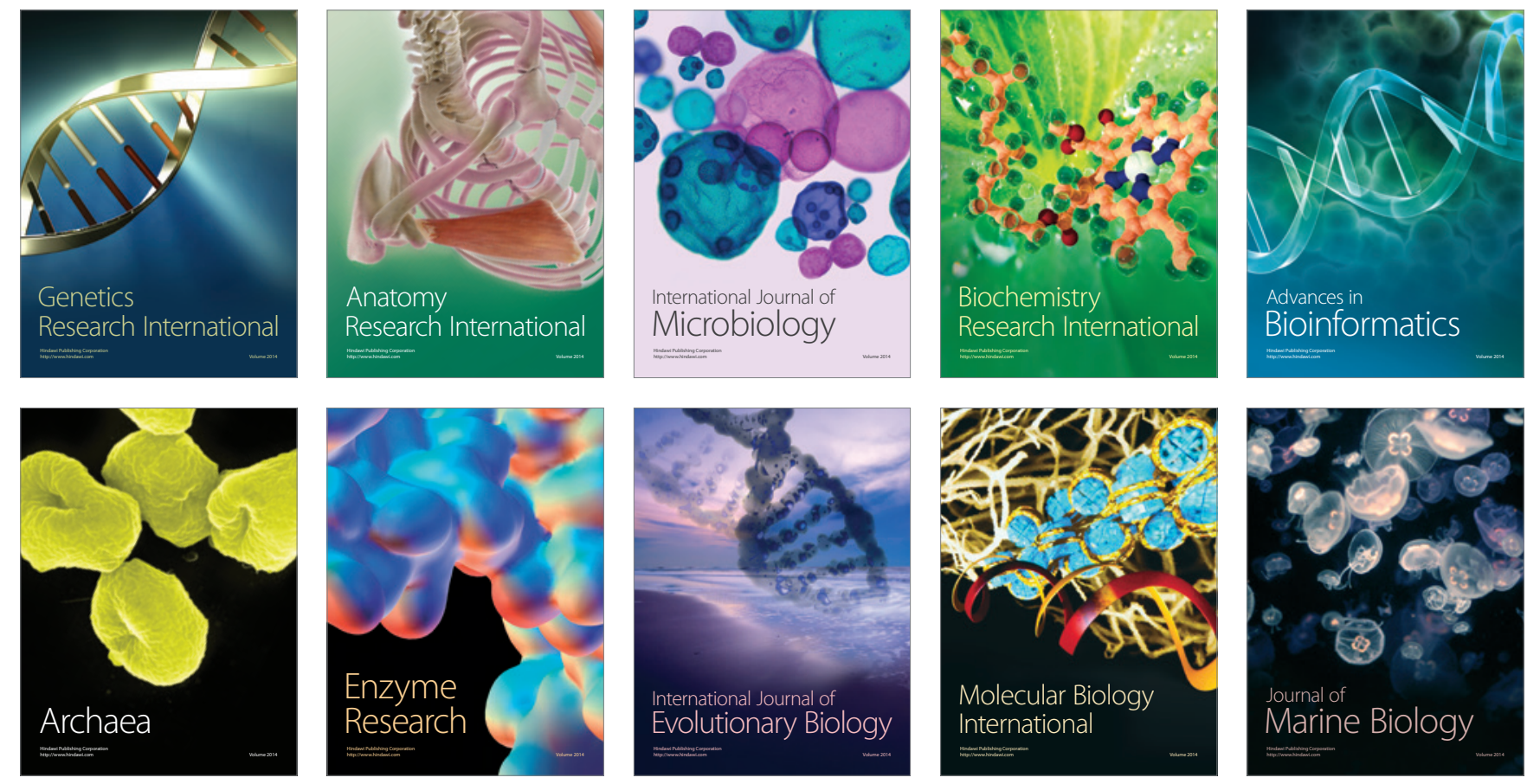